Check for updates

Cite this: RSC Adv., 2018, 8, 6252

Received 21st November 2017 Accepted 1st February 2018

DOI: $10.1039 / c 7 r a 12655 g$

rsc.li/rsc-advances

\section{A TPE-benzothiazole piezochromic and acidichromic molecular switch with high solid state luminescent efficiency $\dagger$}

\author{
Chunping Ma, $\neq^{\text {ab }}$ Jiajun He, $\ddagger^{c}$ Bingjia Xu, ${ }^{d}$ Gaoyi Xie, (D) *ef Zongliang Xie, ${ }^{c}$ Zhu Mao \\ and Zhenguo Chi (D) *c
}

\begin{abstract}
A new organic compound, namely B-TPEAN, was constructed by using tetraphenylethylene, acrylonitrile and benzothiazole as building blocks. Herein, results of single crystal structure analysis and theoretical calculation for the as-synthesized compound were presented. Photophysical properties, including UVvisible absorption, photoluminescence and fluorescent quantum yield, were also well studied. B-TPEAN was found to show excellent aggregation-induced emission (AIE) properties and high quantum yield (up to $85 \%$ in the solid-state. These results should be attributed to the positive effect of a combination of two typical AIE moieties in one molecule. Upon grinding, the emission color of the pristine sample for BTPEAN changed from bluish green $\left(\lambda_{\mathrm{em}, \max }=497 \mathrm{~nm}\right)$ to yellow $\left(\lambda_{\mathrm{em}, \max }=567 \mathrm{~nm}\right)$, exhibiting a remarkable piezochromism. Moreover, by fuming with acid vapor, both of the pristine and the ground samples of B-TPEAN showed dramatic decreases in fluorescence quantum yields and large bathochromic shifts in PL maxima up to $53 \mathrm{~nm}$ and $80 \mathrm{~nm}$, respectively, indicating a success in achieving multi-stimuli-responsive luminophore with high contrast in both emission intensity and color. Further investigation revealed that the acidifluorochormism of the samples was caused by the protonation of the benzothiazole moiety, leading to an enhancement of ICT effect in the protonated molecules.
\end{abstract}

\section{Introduction}

Fluorescent materials which can change their color upon exposure to different environmental stimuli, such as light, ${ }^{1}$ acids/bases, ${ }^{2-4}$ electricity, ${ }^{5}$ mechanical force ${ }^{6-8}$ etc., are of great importance for their potential applications in sensors, memory devices and switches. To achieve the above applications, strong

\footnotetext{
${ }^{a}$ Key Laboratory of Light Metal Materials Processing Technology of Guizhou Province, Guizhou Institute of Technology, Guiyang 550003, China

${ }^{b}$ School of Materials and Metallurgical Engineering, Guizhou Institute of Technology, Guiyang 550003, China

${ }^{\circ} P C F M$ Lab, GDHPPC Lab, Guangdong Engineering Technology Research Center for High-performance Organic and Polymer Photoelectric Functional Films, State Key Laboratory of OEMT, School of Chemistry and Chemical Engineering, Sun Yat-sen University, Guangzhou 510275, China. E-mail: chizhg@mail.sysu.edu.cn

${ }^{d}$ Key Laboratory of Theoretical Chemistry of Environment, Ministry of Education, School of Chemistry and Environment, South China Normal University, Guangzhou 510006, China

${ }^{e}$ College of Chemical Engineering, Guizhou Institute of Technology, Guiyang 550003, China.E-mail: xiegaoyi@126.com

${ }^{f}$ Guizhou Material Industry Technology Research Institute, Guiyang 550014, China. E-mail: xiegaoyi@126.com

$\dagger$ Electronic supplementary information (ESI) available: ${ }^{1} \mathrm{H}$ NMR (Fig. S1), ${ }^{13} \mathrm{C}$ NMR (Fig. S2), MS (Fig. S3), FTIR (Fig. S4) spectra and TGA curve (Fig. S5) of B-TPEAN. CCDC 1509687. For ESI and crystallographic data in CIF or other electronic format see DOI: $10.1039 / \mathrm{c} 7 \mathrm{ra} 12655 \mathrm{~g}$

$\$$ These authors contributed equally to the preparation of this work.
}

emission of fluorescent materials in the solid state is required. Unfortunately, most of the organic dyes quench or weaken their fluorescence in the aggregation state, due to the notorious aggregation caused quenching (ACQ) effect. ${ }^{9,10}$ For example, Li et al. ${ }^{11}$ reported that an imide dye based on tetrahydro[5]helicene skeleton exhibited remarkable and reversible acid/base stimulated fluorescence switching properties in both solution and solid state. However, the quantum yield of the compound in solid state $(7.4 \%)$ was much lower than that in solution ( $75.2 \%$ in cyclohexane and $72.6 \%$ in toluene). A strategy to overcome the ACQ effect is to let the aggregation play positive instead of negative roles in enhancing the efficiency in molecule emission. ${ }^{12}$ The substances with anti-ACQ property are called aggregation-induced emission (AIE) compounds. A class of AIE azobenzene derivatives prepared by Han $e t a l .{ }^{3}$ could turn their emission from a twisted intramolecular charge transfer (TICT) state to a locally excited (LE) state upon alkali treatment. The spectral change could be rehabilitated through thermal treatment. Unfortunately, the quantum yields $(2.4-6.7 \%)$ of the azobenzene derivatives were still low.

Tetraphenylethylene (TPE), due to its propeller-shaped molecular structure, is non-emissive in solution but becomes highly emissive in aggregated state. ${ }^{13}$ Therefore, TPE derivatives with varied optical properties have been hotly investigated. ${ }^{14-17}$ Recently, we have also presented a TPE-base luminophore, i.e. TPENSOH, which contains a functional group of 6- 
hydroxybenzothiazole. This new compound showed a remarkable and reversible four-color switch based on the piezo and protonation-deprotonation control in the solid state. ${ }^{\mathbf{1 8}}$ Although TPENSOH exhibited stronger luminescence in comparison with most of the acid/base-stimuli-responsive emitters, its fluorescence quantum yield (around 0.3) remain moderate among the whole AIEgen family. As reported previously, ${ }^{\mathbf{1 , 1 7 , 1 9 , 2 0}}$ aromatic-substituted acrylonitrile derivatives have been proved to be AIE-active and possess a strong fluorescence emission in solid-state. Furthermore, combining two AIE moieties in a single molecule probably can endow the luminophore with stronger fluorescence emission. Accordingly, an acrylonitrile group was introduced to link a TPE and a benzothiazole fragments to create a novel molecule of B-TPEAN, which contains two typical AIE moieties. It is expected that the well-designed compound could show multi-color fluorescent switch with even higher quantum yield. The molecular structure of B-TPEAN was fully characterized by ${ }^{1} \mathrm{H}$ NMR, ${ }^{13} \mathrm{C}$ NMR, FT-IR, mass spectra and single-crystal X-ray diffraction analysis. The optical properties of B-TPEAN were measured by UV-visible absorption spectroscopy and fluorescence spectroscopy. The piezochromism of B-TPEAN was discussed based on the results of PXRD and DSC measurements, which were also used to characterize the changes of aggregation structures.

\section{Materials and methods}

\subsection{Material}

1-Bromo-1,2,2-triphenylethene $\left(\mathrm{P}_{3} \mathrm{Br}\right)$, 4-formylphenylboronic acid, tetrabutyl ammonium bromide (TBAB), tetrakis(triphenylphosphine)palladium $\left[\mathrm{Pd}\left(\mathrm{PPh}_{3}\right)_{4}\right]$, benzothiazole-2acetonitrile and tetrabutylammonium hydroxide were purchased from Alfa Aesar and were used as received. Potassium carbonate $\left(\mathrm{K}_{2} \mathrm{CO}_{3}\right)$, potassium hydroxide $(\mathrm{KOH})$, toluene, ethanol were purchased as analytical grade from Sinopharm Chemical Reagent Co., Ltd (Shanghai, China) and used without further purification.

\subsection{General procedure for B-TPEAN}

The compound of $\mathrm{P}_{4} \mathrm{~A}$ was prepared by using a previous literature method. ${ }^{17}$

Synthesis of $(E)-2-($ benzo[ $[d]$ thiazol-2-yl)-3-(4-(1,2,2-triphenylvinyl)phenyl)acrylonitrile (B-TPEAN). A solution of $\mathrm{P}_{4} \mathrm{~A}$ $(1.00 \mathrm{~g}, 2.77 \mathrm{mmol})$ and benzothiazole-2-acetonitrile $(0.56 \mathrm{~g}$, $3.19 \mathrm{mmol})$ in ethanol $(30 \mathrm{~mL})$ was stirred at room temperature. Then tetrabutylammonium hydroxide (TBAH, 0.8 M, 10 drops) was added and the mixture was stirred at room temperature for $4 \mathrm{~h}$. The precipitate was collected and washed with ethanol for three times to afford a yellow-green powder $(1.30 \mathrm{~g}$, yield $91 \%) .{ }^{1} \mathrm{H}$ NMR (300 MHz, $\left.\mathrm{CDCl}_{3}\right) \delta(\mathrm{ppm}): 8.16(\mathrm{~s}, 1 \mathrm{H}), 8.08(\mathrm{~d}, 1 \mathrm{H}, J=7.7$ $\mathrm{Hz}), 7.90(\mathrm{~d}, 1 \mathrm{H}, J=8.0 \mathrm{~Hz}), 7.79(\mathrm{~d}, 2 \mathrm{H}, J=8.29 \mathrm{~Hz}), 7.53(\mathrm{t}, 1 \mathrm{H}, J$ $=7.56 \mathrm{~Hz}), 7.43(\mathrm{t}, 1 \mathrm{H}, J=7.59 \mathrm{~Hz}), 6.99-7.20(\mathrm{~m}, 17 \mathrm{H}) .{ }^{13} \mathrm{C} \mathrm{NMR}$ (75 MHz, $\left.\mathrm{CDCl}_{3}\right) \delta(\mathrm{ppm}): 164.40,155.06,149.88,147.85,144.47$, 144.32 , 141.21, 136.33, 133.56, 132.73, 132.64, 131.70, 131.29, $129.35,129.09$, 128.50, 128.25, 127.27, 124.93, 123.00, 117.99,
105.96. FT-IR (KBr): 3022, 2220, 1585, 1489, 1441, 822, 762, 698. EI-MS, $m / z: 516\left([\mathrm{M}]^{+}\right.$, calcd for $\left.\mathrm{C}_{36} \mathrm{H}_{24} \mathrm{~N}_{2}, 516\right)$.

\subsection{Characterization}

${ }^{1} \mathrm{H}$ NMR and ${ }^{13} \mathrm{C}$ NMR spectra were measured on a Mercury-Plus 300 spectrometer $\left[\mathrm{CDCl}_{3}\right.$ as solvent and tetramethylsilane (TMS) as the internal standard]. FT-IR analyses were carried out on a Nicolet NEXUS 670 spectrometer (KBr pellet). Mass spectra (MS) were obtained via a Thermo DSQ MS spectrometer (ionization method: EI). UV-visible absorption spectra (UV-vis) were performed on a Hitachi U-3900 spectrophotometer. Fluorescence spectra (PL) were determined on a Shimadzu RF-5301PC spectrometer with a slit width of $1.5 \mathrm{~nm}$ for excitation and $3 \mathrm{~nm}$ for emission. Differential scanning calorimetry (DSC) on a NETZSCH thermal analyzer (DSC 204F1) was used to investigate thermal behaviors at both heating and cooling rates of $10{ }^{\circ} \mathrm{C} \min ^{-1}$ under a $\mathrm{N}_{2}$ atmosphere. Time-resolved emission decay behaviors were measured on an Edinburgh Instruments Ltd spectrometer (FLS 920). Powder X-ray diffraction (PAXD) measurements were performed at $293 \mathrm{~K}$ on a Bruker X-ray diffractometer (D8 ADVANCE, Germany) with an X-ray source of $\mathrm{Cu} \mathrm{K} \alpha(\lambda=0.15406 \mathrm{~nm})$ at $40 \mathrm{kV}$ and $40 \mathrm{~mA}$, at a scan rate of $6^{\circ}(2 \theta)$ per min. Fluorescence quantum yields of solid powders were measured on an integrating sphere (C-701, Labsphere Inc.), with a $405 \mathrm{~nm}$ Ocean Optics LLS-LED as the excitation source, and the light was introduced into the integrating sphere through optical fiber.

The single crystal of the compound was grown from a dichloromethane/ethanol mixture through slow volatilization. X-Ray crystallographic intensity data were collected from an Agilent Technologies Gemini A Ultra system with $\mathrm{Cu}-\mathrm{K} \alpha$ radiation $(\lambda=1.54178 \AA)$ at $150.01(10) \mathrm{K}$. The structure was solved by the direct methods following difference Fourier syntheses, and refined by the full-matrix least-squares method against $F^{2}$ using SHELXTL software (CCDC 1509687 $\dagger$ ). The pictures of the structure were produced using Diamond 3.1.

TD-DFT calculations of electronic cloud density distribution based on the single crystal structure were performed on Gaussian 09 program at the B3lyp 6-311+g(d,p) level of the theory.

\section{Results and discussion}

The synthetic routes of B-TPEAN are illustrated in Scheme 1. Briefly, B-TPEAN was synthesized by the Suzuki and the Knoevenagel condensation reactions. The chemical structure of $\mathbf{B}-$ TPEAN was confirmed by ${ }^{1} \mathrm{H}$ NMR, ${ }^{13} \mathrm{C}$ NMR, FT-IR and MS analyses (Fig. S1-S4, ESI $\dagger$ ). The temperature of weight loss at $5 \%$ under nitrogen was determined to be $362{ }^{\circ} \mathrm{C}$ (Fig. S5, $\mathrm{ESI} \dagger$ ), indicating that B-TPEAN has high thermal stability.

Single crystals of B-TPEAN were obtained by using the slow volatilization method and the crystal structure was determined by single-crystal X-ray diffraction analysis. As depicted in Table 1 , the single crystal of B-TPEAN belongs to the monoclinic system. While the single molecular conformation and the intermolecular interactions are illustrated in Fig. 1, the dihedral 
<smiles>BrC(=C(c1ccccc1)c1ccccc1)c1ccccc1</smiles>

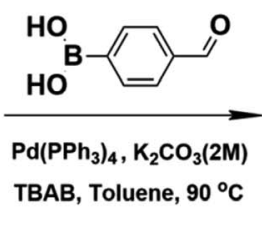

$\mathrm{P}_{3} \mathrm{Br}$<smiles>O=Cc1ccc(C(=C(c2ccccc2)c2ccccc2)c2ccccc2)cc1</smiles>

$\mathbf{P}_{4} \mathbf{A}$

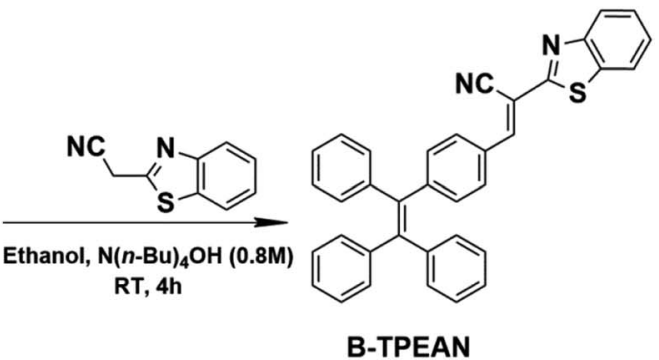

B-TPEAN

Scheme 1 Synthetic routes of B-TPEAN.

Table 1 Crystal data and structure refinements for the single crystal of B-TPEAN

\begin{tabular}{ll}
\hline Compound & B-TPEAN \\
Formula & $\mathrm{C}_{36} \mathrm{H}_{24} \mathrm{~N}_{2} \mathrm{~S}$ \\
fw & 516.63 \\
Crystal system & Triclinic \\
$T(\mathrm{~K})$ & $150.01(10)$ \\
Space group & $P \overline{1}$ \\
$a / \AA$ & $10.3022(6)$ \\
$b / \AA$ & $10.3149(7)$ \\
$c / \AA$ & $13.7990(8)$ \\
$\alpha /{ }^{\circ}$ & $110.494(6)$ \\
$\beta /{ }^{\circ}$ & $96.161(5)$ \\
$\gamma /{ }^{\circ}$ & $98.769(5)$ \\
$V / \AA^{3}, Z$ & $1336.89(14), 2$ \\
$F(000)$ & 522 \\
Crystal size/mm ${ }^{3}$ & $0.32 \times 0.20 \times 0.15$ \\
Reflns collected/unique $\left(R_{\text {int }}\right)$ & $7270 / 4349\left(R_{\text {int }}=0.0187\right)$ \\
Obsd reflns $[I \geq 2 \sigma(I)]$ & 3743 \\
Data/restraints/parameter & $4349 / 0 / 352$ \\
$D_{\mathrm{c}} / \mathrm{mg} \mathrm{m}^{-3}$ & 1.239 \\
$\mu / \mathrm{mm}^{-1}$ & 1.286 \\
${\text { Goodness-of-fit on } F^{2}}_{R_{1}{ }^{a}{ }^{\circ} R_{2}{ }^{b}[I \geq 2 \sigma(I)]}$ & 1.032 \\
$R_{1}, \mathrm{w}_{2}($ all data $)$ & $0.0320 / 0.0798$ \\
${ }^{\circ}{ }^{\circ}$ & $0.0392 / 0.0845$
\end{tabular}

${ }^{a} R_{1}=\Sigma|| F_{\mathrm{o}}|-| F_{\mathrm{c}}|| / \Sigma\left|F_{\mathrm{o}}\right|{ }^{b} \mathrm{w} R_{2}=\left[\Sigma\left[w\left(F_{\mathrm{o}}{ }^{2}-F_{\mathrm{c}}{ }^{2}\right)^{2}\right] / \Sigma w\left(F_{\mathrm{o}}{ }^{2}\right)^{2}\right]^{1 / 2}$, where $w=1 /\left[\sigma^{2}\left(F_{\mathrm{o}}\right)^{2}+(a P)^{2}+b P\right]$ and $P=\left(F_{\mathrm{o}}{ }^{2}+2 F_{\mathrm{c}}{ }^{2}\right) / 3$.
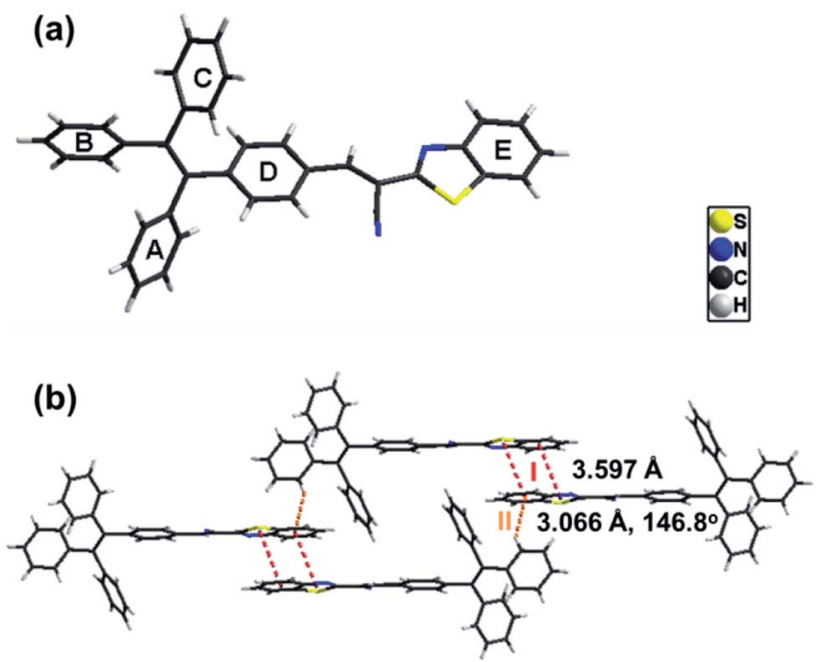

Fig. 1 Crystal structure and the intermolecular interactions of BTPEAN.

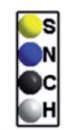

Table 2 The dihedral angles of the selected planes of the molecule in single crystal of B-TPEAN

\begin{tabular}{llll}
\hline Plane & Dihedral angle ${ }^{\circ}$ & Plane & Dihedral angle $/^{\circ}$ \\
\hline A-B & 56.6 & B-D & 79.6 \\
A-C & 76.6 & C-D & 59.8 \\
A-D & 75.1 & D-E & 2.9 \\
B-C & 74.1 & & \\
\hline
\end{tabular}

angles between the aryl rings as defined in Fig. 1(a) were calculated and collected in Table 2 . The TPE moiety of B-TPEAN in single crystal structure shows a twisted conformation and thereby no obvious $\pi \cdots \pi$ interaction was observed between any phenyl rings of the neighboring TPE moieties (Fig. 1(a)). Instead, one of the phenyl rings of TPE forms weak $\mathrm{C}-\mathrm{H} \cdots \pi$ (tail-to-head) interaction with the phenyl ring of benzothiazole in the neighbouring molecule (Fig. 1(b)).

On the other hand, the benzothiazole moieties of two adjacent molecules adopt antiparallel coupling (dihedral angle $0.25^{\circ}$ ) and form strong $\pi \cdots \pi$ (tail-to-tail) interaction with each other. Such stable molecular conformation and intermolecular interactions could efficiently block the non-radiative pathways (rotation) of the excitons, which is beneficial for harvesting high B-TPEAN fluorescent quantum yield.

\section{B3lyp 6-311+g(d,p)}

Dipole moment:3.6709D, $f=0.6983$

135-HOMO

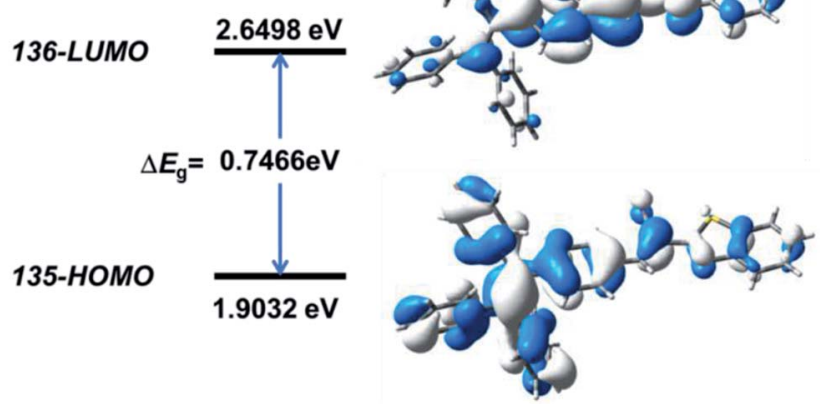

Fig. 2 Calculated spatial electron distributions of $\mathrm{HOMO}$ and LUMO of B-TPEAN. 
Quantum mechanical calculations based on the density functional theory were performed to investigate the electron transition behavior of B-TPEAN. As shown in Fig. 2, the highest occupied molecular orbital (HOMO) of B-TPEAN shows dispersed electron cloud distribution at the TPE moiety, whereas the electron cloud of the lowest unoccupied molecular orbital (LUMO) is principally located at the vinyl group of the AN moiety and the neighbouring benzene ring of the TPE moiety. The B-TPEAN molecule showed large dipole moment (3.6709 D) and high oscillator strength $(f=0.6983)$, implying strong intramolecular electron push-pull effect and high fluorescent quantum yield of B-TPEAN. These theoretical calculation results suggested that B-TPEAN had ICT characteristics, from the TPE (donor) moiety to the benzothiazole (acceptor) moiety. In other words, benzothiazole is electron-withdrawing compared with the TPE moiety.

To determine the AIE feature of B-TPEAN, the emission behavior of the compound in solvent-nonsolvent system was investigated. Fig. 3 shows the PL emission spectra of the luminophore in THF/water mixtures with different water fractions. Under the illumination of UV lamp, the THF solution of BTPEAN showed a very weak bluish-green fluorescence centered at $475 \mathrm{~nm}$. When water was added, the fluorescence was even quenched, probably due to the TICT effect. However, when the water fraction increased to $80 \%$, strong yellow-green fluorescence $(\sim 540 \mathrm{~nm})$ appeared. The photoluminescence (PL) intensity of the B-TPEAN THF/water mixture with $90 \%(\mathrm{v} / \mathrm{v})$ water fraction $(\sim 213$ a.u.) was increased by up to almost 20 times as compared with that of the pure THF solution $(\sim 11$ a.u.), implying a remarkable AIE phenomenon. When the water fraction further increased (95\%), the PL intensity of the mixture decreased slightly, attributed to the increased size of the BTPEAN aggregates, which reduced the number of the emission molecules on the surface of the nanoparticles. ${ }^{21}$

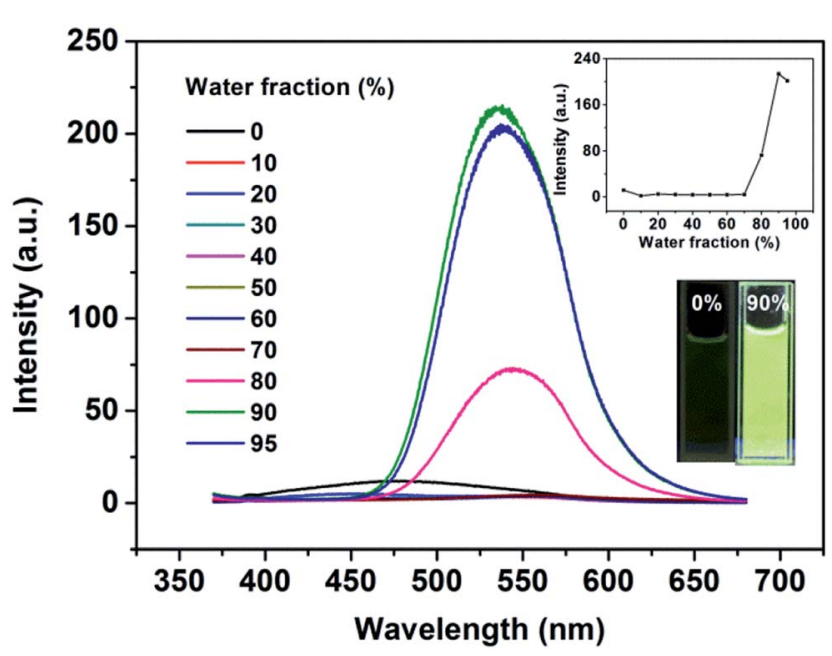

Fig. $3 \mathrm{PL}$ spectra of the dilute solutions of B-TPEAN in THF/water mixtures with different water fractions (concentration: $10 \mu \mathrm{M}$; excitation wavelength: $365 \mathrm{~nm}$ ). The insets depict the changes in $\mathrm{PL}$ peak intensity (up) and emission images of B-TPEAN in pure THF and THF/ water (9:1, v/v) under $365 \mathrm{~nm}$ UV illumination (down).

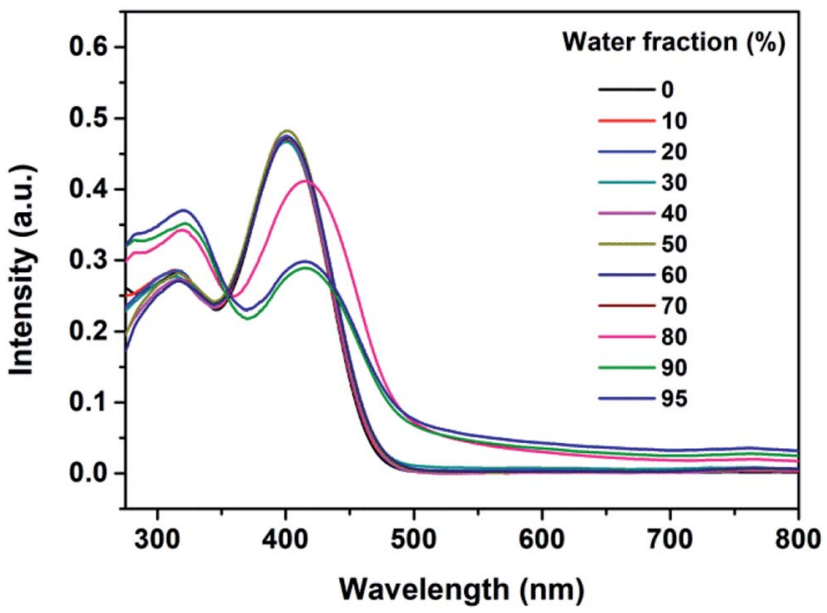

Fig. 4 UV-visible spectra of the dilute solutions of B-TPEAN in THF/ water mixtures with different water fractions (concentration: $10 \mu \mathrm{M}$ ).

Fig. 4 presents UV-vis absorption spectra of the B-TPEAN mixtures noted above. The spectral profiles significantly changed when the water fraction was higher than $80 \%$. Two absorption peaks red shifted from $315 \mathrm{~nm}$ to $320 \mathrm{~nm}$ and from $402 \mathrm{~nm}$ to $415 \mathrm{~nm}$, respectively. Moreover, the UV-visible absorption spectra showed a Mie scattering effect for the mixtures, which proved the existence of nanoparticles. The results of UV-visible absorption corresponded well with the changes of PL spectra, thus indicating that the emission enhancement of B-TPEAN at high water content was caused by molecular aggregation. In other words, B-TPEAN is AIE-active.

The AIE characteristic of B-TPEAN encouraged us to investigate its emission behavior in the solid state. As shown in Fig. 5, the pristine B-TPEAN solid powder (B) exhibits a strong blue-green-light emission centered at $497 \mathrm{~nm}$, with a high fluorescence quantum yield of $50 \%$. After being ground by a pestle or sheared by a spatula, the resultant powder (G) emitted a yellow-light and the corresponding fluorescence quantum yield decreased $\left(\Phi_{\mathrm{F}, \mathrm{s}}=42 \%\right)$ slightly. Meanwhile, the PL maximum of B-TPEAN shifted to $567 \mathrm{~nm}$, exhibiting a remarkable emission wavelength change of $70 \mathrm{~nm}$. Many piezochromic compounds could recover their emission colors upon heating or solvent fuming. ${ }^{17,22-24}$ In this system, after being heated $\left(130{ }^{\circ} \mathrm{C}\right)$ or fumed with $\mathrm{CH}_{2} \mathrm{Cl}_{2}$, the resultant BTPEAN powders (A and $\mathrm{F}_{\mathrm{CH}_{2} \mathrm{Cl}_{2}}$, respectively) displays a yellowgreen light emission centered at $541 \mathrm{~nm}$ or $545 \mathrm{~nm}$, respectively, which is almost the same with that of the single crystal (C) of B-TPEAN (centered at $544 \mathrm{~nm}$ ). These color changes seem to be irreversible under these treatment conditions. However, unexpectedly, even higher fluorescence quantum yields were observed for the annealed sample $\left(\Phi_{\mathrm{F}, \mathrm{s}}=57 \%\right)$ and the fumed sample $\left(\Phi_{\mathrm{F}, \mathrm{s}}=85 \%\right)$. To gain an understanding for these phenomena, PXRD and DSC were carried out for the samples of B-TPEAN.

Fig. 6 shows the PXRD patterns of the B-TPEAN powders. The B powder exhibits sharp and intense reflections. Upon grinding, the intensity of PXRD pattern decreased, indicating that the 

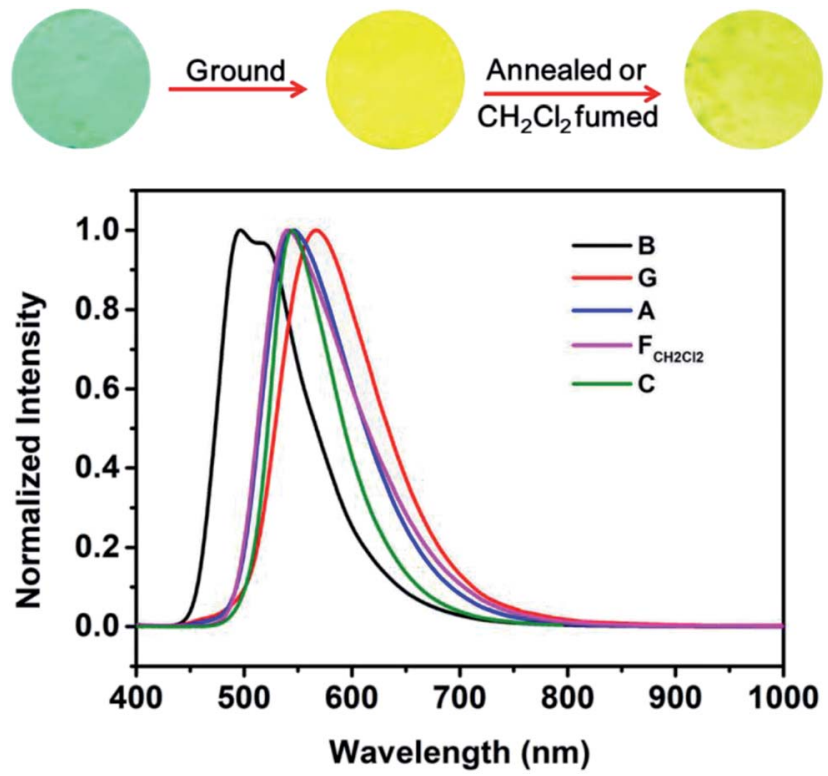

Fig. 5 Fluorescence images and normalized PL spectra of B-TPEAN: (B) the pristine powder, (G) ground powder from $B$, (A) annealed (130 ${ }^{\circ} \mathrm{C}, 15 \mathrm{~min}$ ) powder from $\mathrm{G}$; $\left(\mathrm{F}_{\mathrm{CH}_{2} \mathrm{Cl}_{2}}\right) \mathrm{CH}_{2} \mathrm{Cl}_{2}$ fumed (10 min) powder from G; (C) single crystal.

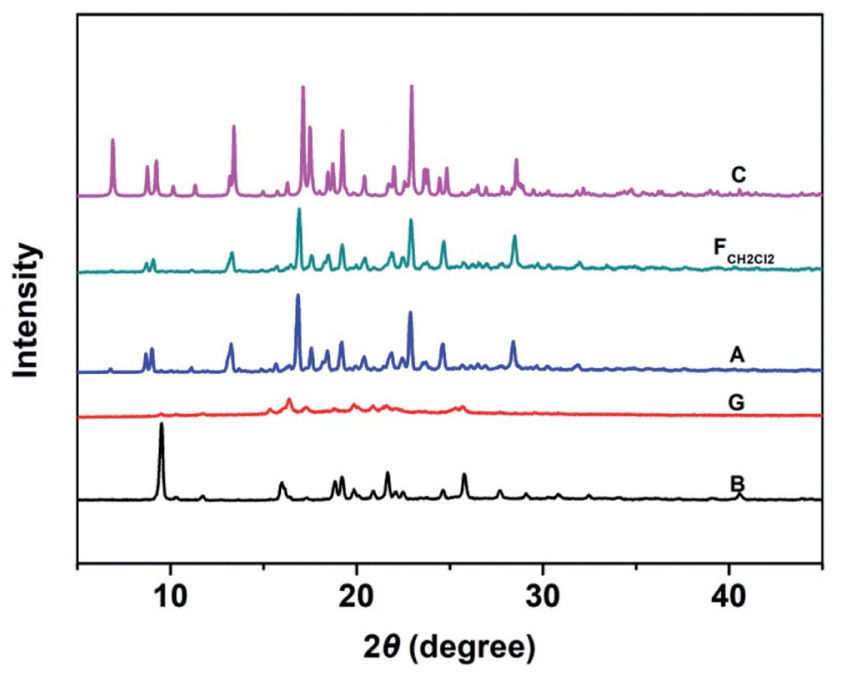

Fig. 6 The PXRD patterns of B-TPEAN: (B) the pristine powder, (G) ground powder from $\mathrm{B},(\mathrm{A})$ annealed $\left(130^{\circ} \mathrm{C}, 15 \mathrm{~min}\right)$ powder from $\mathrm{G}$; $\left(\mathrm{F}_{\mathrm{CH}_{2} \mathrm{Cl}_{2}}\right) \mathrm{CH}_{2} \mathrm{Cl}_{2}$ fumed (10 min) powder from $\mathrm{G}$; (C) single crystal.

crystalline phase of B-TPEAN almost converted to amorphous phase, which would reduce the quantum yield of the ground powder. However, the ground sample is a metastable state, and it will rapidly crystallize again if it is annealed or fumed by $\mathrm{CH}_{2} \mathrm{Cl}_{2}$. Interestingly, compared with the B powder, both of the PXRD patterns for $\mathrm{A}$ and $\mathrm{F}_{\mathrm{CH}_{2} \mathrm{Cl}_{2}}$ are totally different, but are accorded well with the PXRD pattern of the $\mathrm{C}$ powder. It seems that the crystal state of the B powder is unstable and would convert to a new one by grinding and subsequent annealing/ fuming treatments. To verify this hypothesis, differential

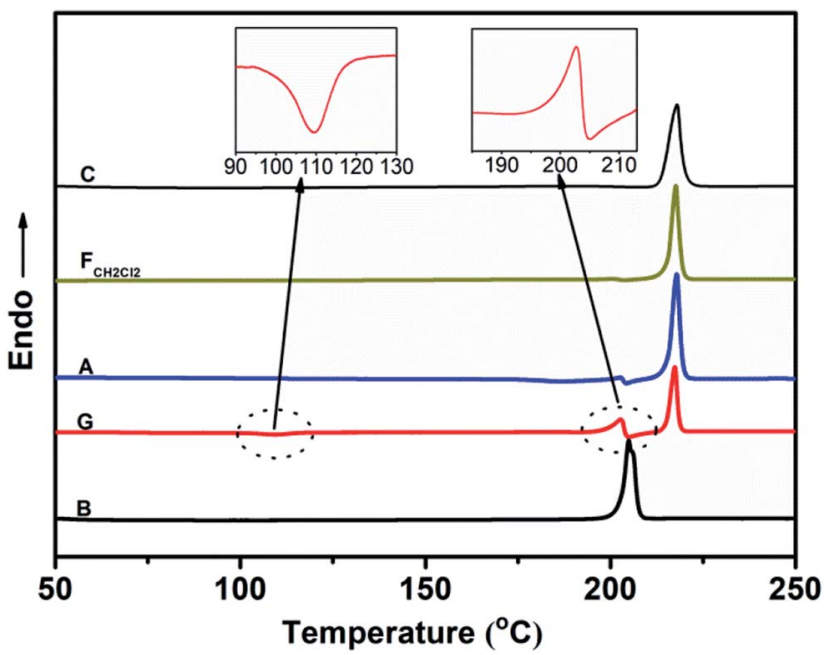

Fig. 7 DSC curves of B-TPEAN: (B) the pristine powder, (G) ground powder from $\mathrm{B},(\mathrm{A})$ annealed $\left(130{ }^{\circ} \mathrm{C}, 15 \mathrm{~min}\right)$ powder from $\mathrm{G}$; $\left(\mathrm{F}_{\mathrm{CH}_{2} \mathrm{Cl}_{2}}\right)$ $\mathrm{CH}_{2} \mathrm{Cl}_{2}$ fumed (10 min) powder from $\mathrm{G}$; (C) single crystal.

scanning calorimetry (DSC) was also performed to investigate to the thermal behaviors of B-TPEAN. As illustrated in Fig. 7, the B powder shows an obvious endothermal peak at $205{ }^{\circ} \mathrm{C}$. However, for the $\mathrm{G}$ powder, the intensity of the endothermal peak $\left(\sim 203{ }^{\circ} \mathrm{C}\right)$ decreased. Furthermore, an additional exothermal peak at approximately $110{ }^{\circ} \mathrm{C}$ was observed, fully demonstrating that the microcrystals of the ground sample were partially destroyed and converted to the amorphous state by grinding treatment. An exothermal peak $\left(\sim 205^{\circ} \mathrm{C}\right)$, which could be assigned to a cold crystallization peak, and a new endothermal peak at a higher temperature $\left(\sim 217^{\circ} \mathrm{C}\right)$ was also observed, suggesting that a more stable crystal structure of $\mathbf{B}$ TPEAN was formed. The appearance of the latter endothermal peak might be attributed to the heating measurement, which induced crystallization of B-TPEAN. Indeed, after annealing or fuming treatment, an obvious endothermal peak at $217-218^{\circ} \mathrm{C}$ was also observed, whereas the endothermal peak at $205{ }^{\circ} \mathrm{C}$ almost disappeared. More importantly, the $\mathrm{C}$ powder also shows its endothermal peak at $218{ }^{\circ} \mathrm{C}$, revealing that the thermal behaviors of the $\mathrm{A}$ and $\mathrm{F}_{\mathrm{CH}_{2} \mathrm{Cl}_{2}}$ powders are similar with that of the $\mathrm{C}$ powder, but not the $\mathrm{B}$ powder. The PXRD and DSC results demonstrate that the crystal structures of $\mathrm{A}$ and $\mathrm{F}_{\mathrm{CH}_{2} \mathrm{Cl}_{2}}$ powders are completely different from that of the B powder, giving a rational explanation for the emission behaviors of the B-TPEAN powders.

Considering that benzothiazole moiety can be easily protonated by acid and then change the PL emission of the compound, ${ }^{18}$ the emissions of the original and ground samples of B-TPEAN were investigated after treating with acid vapor. As can be seen in Fig. 8, when the B powder was exposed to a $\mathrm{HCl}$ vapor for 1 hour, the luminescence changed from an initial strong blue-green light to a weak orange light with a relatively low $\Phi_{\mathrm{F}, \mathrm{S}}$ value (15\%), which is less than one-third of the one for the $\mathrm{B}$ powder. Furthermore, the PL spectrum of the $\mathrm{F}_{\mathrm{HCl}}$ powder red shifted to $550 \mathrm{~nm}$ with a broad emission band. The decrease 

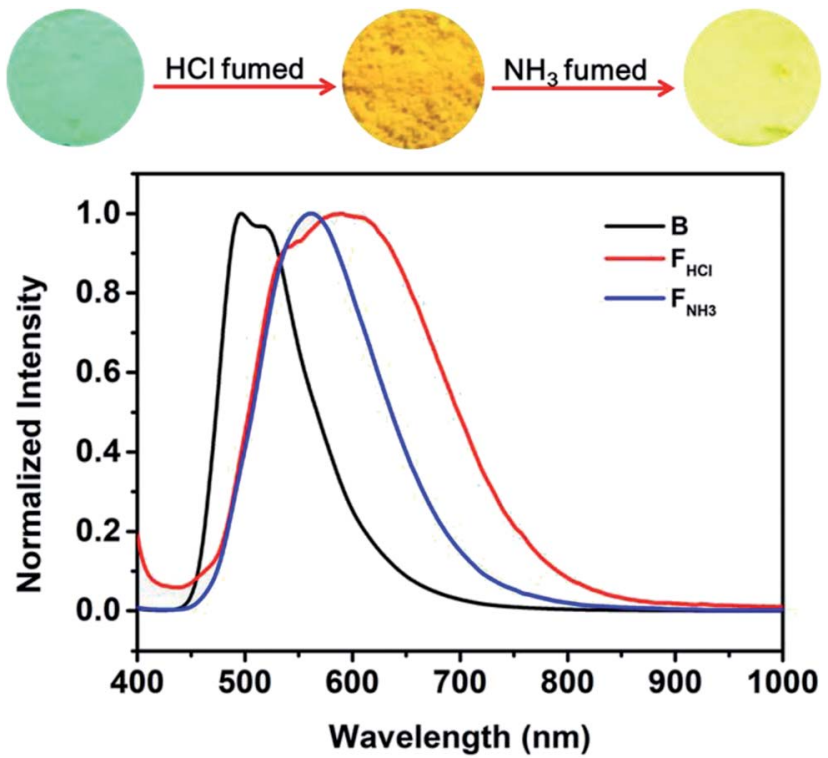

Fig. 8 Fluorescence images and normalized PL spectra of B-TPEAN: (B) the pristine powder; $\left(\mathrm{F}_{\mathrm{HCl}}\right) \mathrm{HCl}$ fumed $(1 \mathrm{~h})$ powder from $\mathrm{B}(\mathrm{HCl}$ gas was released from a $37 \%$ concentrated hydrochloric acid solution); $\left(\mathrm{F}_{\mathrm{NH}_{3}}\right) \mathrm{NH}_{3}$ fumed (30 min) powder from $\mathrm{B}$.

in fluorescence quantum yield and the red-shift of PL spectrum for the $\mathrm{F}_{\mathrm{HCl}}$ sample should be attributed to the protonation of the benzothiazole moiety, leading to the enhancement of intramolecular charge transfer (ICT) from the TPE unit to the benzothiazole moiety. As a result, stronger intermolecular interactions were formed. ${ }^{18,25}$ Subsequently, the $\mathrm{F}_{\mathrm{HCl}}$ powder was exposed to $\mathrm{a} \mathrm{NH}_{3}$ vapor for $30 \mathrm{~min}$ and the resultant powder $\left(\mathrm{F}_{\mathrm{NH}_{3}}\right)$ was found to emit a bright yellow light with a very high $\Phi_{\mathrm{F}, \mathrm{S}}$ value $(74 \%)$, confirming the quenching effect of the
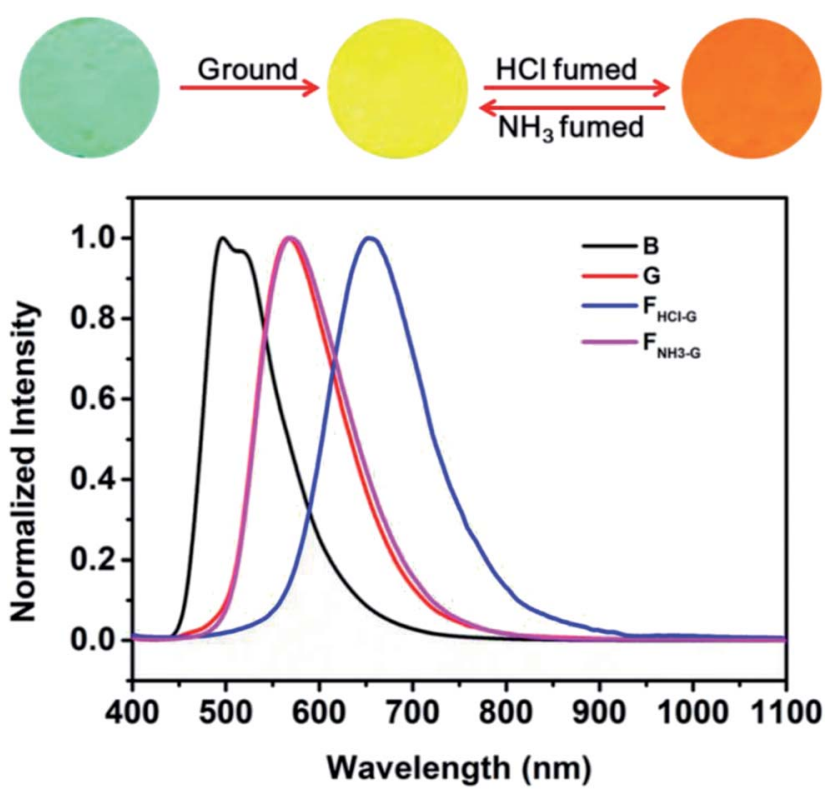

Fig. 9 Fluorescence images and normalized PL spectra of B-TPEAN (B) the pristine powder; $(\mathrm{G})$ ground powder from $\mathrm{B}$; $\left(\mathrm{F}_{\mathrm{HCl}-\mathrm{G}}\right) \mathrm{HCl}$ fumed (20 min) powder from $\mathrm{G}$; $\left(\mathrm{F}_{\mathrm{NH}_{3}-\mathrm{G}}\right) \mathrm{NH}_{3}$ fumed $(10 \mathrm{~min})$ powder from $\mathrm{G}$. protonation process. It is worth to note that the whole PL emission band of the $\mathrm{F}_{\mathrm{NH}_{3}}$ sample overlapped a part of the broad spectrum of the $\mathrm{F}_{\mathrm{HCl}}$ sample. This might be caused by the tight molecular packing of B-TPEAN in the pristine crystalline powder, which gave rise to a slightly low protonation efficiency of B-TPEAN.

As noted above, grinding treatment could destroy the crystal structure of the pristine B-TPEAN. Therefore, we proposed that the $G$ powder would be much easier to be protonated by the acid vapor. As expected, when the G powder was exposed to $\mathrm{HCl}$ vapor for about $20 \mathrm{~min}\left(\mathrm{~F}_{\mathrm{HCl}-\mathrm{G}}\right)$, the fluorescence of the powder changed to be orange $\left(\Phi_{\mathrm{F}, \mathrm{S}}=9 \%\right)$ and a narrow PL emission band centered at $654 \mathrm{~nm}$ was recorded (Fig. 9). Notably, by fuming with the $\mathrm{NH}_{3}$ vapor for $10 \mathrm{~min}\left(\mathrm{~F}_{\mathrm{NH}_{3}-\mathrm{G}}\right)$, the fluorescence of the protonated ground sample could completely reverse back to yellow $\left(\Phi_{\mathrm{F}, \mathrm{S}}=50 \%\right)$, which agreed well with that of the $\mathrm{G}$ powder. The large bathochromic shift up to $87 \mathrm{~nm}$ in emission maxima and the recovery toward the initial state fully demonstrate that the ground sample of B-TPEAN exhibit remarkable and reversible fluorescent switching under the stimuli of acid and base vapor, which is promising in bioimaging and anticounterfeit applications.

\section{Conclusions}

A TPE derivative, namely B-TPEAN, was synthesized through the reaction of Knoevenagel condensation in high yield $(>90 \%)$. BTPEAN showed prominent AIE property that the PL intensity of the mixture with $90 \%(\mathrm{v} / \mathrm{v})$ water content was increased by up to almost 20 times as compared with that of at a water fraction of $0 \%$. In solid state, the B-TPEAN powders have much higher fluorescent quantum yields (up to $85 \%$ ) in comparison with most of the documented luminophores due to the rational combination of two typical AIE moieties (i.e. TPE and arylsubstituted acrylonitrile). PXRD and DSC analysis revealed that, the pristine sample of B-TPEAN was crystalline and metastable. Upon grinding and then annealing or fuming with $\mathrm{CH}_{2} \mathrm{Cl}_{2}$ vapor, the original sample could convert to a new packing mode. Moreover, under the stimulus of acid vapor, both of the pristine and the ground samples of B-TPEAN exhibit remarkable red-shift in PL maxima and dramatical decrease in emission quantum yields because of the stronger ICT effect in the protonated molecules. Additionally, compared to the pristine crystals, the ground sample of B-TPEAN in amorphous state was much easier to be protonated by $\mathrm{HCl}$ vapor. This work offers a new strategy to prepare multi-stimuli-responsive fluorescent switches with high contrast in emission color and high quantum yield.

\section{Conflicts of interest}

There are no conflicts to declare.

\section{Acknowledgements}

These authors contributed equally to the preparation of this work. This research was supported by the National Science 
Foundation of China (Nos. 51503046, 51603233, 51473185 and 51603232), 863 Program (SS2015AA031701), the Guizhou Province Science and Technology Planning Project (Nos. [2015]2068 and [2015]2078) and the Research Project for High-level Talents of Guizhou Institute of Technology (XJGC201503).

\section{References}

1 J. W. Chung, S.-J. Yoon, S.-J. Lim, B.-K. An and S. Y. Park, Angew. Chem., Int. Ed., 2009, 48, 7030-7034.

2 J. Zhang, J. Chen, B. Xu, L. Wang, S. Ma, Y. Dong, B. Li, L. Ye and W. Tian, Chem. Commun., 2013, 49, 3878-3880.

3 L. Hu, Y. Duan, Z. Xu, J. Yuan, Y. Dong and T. Han, J. Mater. Chem. C, 2016, 4, 5334-5341.

4 Z. Zeng, J. Wen, H. Yan, Z. Liu, Y. Xu, H. Li, C. Zhong, F. Liu and S. Sun, RSC Adv., 2016, 6, 37385-37390.

5 H. Niu, P. Luo, M. Zhang, L. Zhang, L. Hao, J. Luo, X. Bai and W. Wang, Eur. Polym. J., 2009, 45, 3058-3071.

6 W. Liu, S. Ying, Q. Sun, X. Qiu, H. Zhang, S. Xue and W. Yang, Dyes Pigm., 2016, 125, 8-14.

7 M. Zheng, M. Sun, Y. Li, J. Wang, L. Bu, S. Xue and W. Yang, Dyes Pigm., 2014, 102, 29-34.

8 K.-Y. Zhao, G.-G. Shan, Q. Fu and Z.-M. Su, Organometallics, 2016, 35, 3996-4001.

9 R. Jakubiak, C. J. Collison, W. C. Wan, L. J. Rothberg and B. R. Hsieh, J. Phys. Chem. A, 1999, 103, 2394-2398.

10 S. W. Thomas, G. D. Joly and T. M. Swager, Chem. Rev., 2007, 107, 1339-1386.

11 M. Li, Y. Niu, H.-Y. Lu and C.-F. Chen, Dyes Pigm., 2015, 120, 184-189.

12 M. Chen, L. Li, H. Nie, J. Tong, L. Yan, B. Xu, J. Z. Sun, W. Tian, Z. Zhao and A. Qin, Chem. Sci., 2015, 6, 1932-1937.
13 Y. Dong, J. W. Y. Lam, A. Qin, J. Liu, Z. Li, B. Z. Tang, J. Sun and H. S. Kwok, Appl. Phys. Lett., 2007, 91, 011111.

14 Q. Qi, X. Fang, Y. Liu, P. Zhou, Y. Zhang, B. Yang, W. Tian and S. X.-A. Zhang, RSC Adv., 2013, 3, 16986-16989.

15 Q. Qi, Y. Liu, X. Fang, Y. Zhang, P. Chen, Y. Wang, B. Yang, B. Xu, W. Tian and S. X.-A. Zhang, RSC Adv., 2013, 3, 79968002.

16 T. Jadhav, B. Dhokale, Y. Patil, S. M. Mobin and R. Misra, J. Phys. Chem. C, 2016, 120, 24030-24040.

17 B. Xu, M. Xie, J. He, B. Xu, Z. Chi, W. Tian, L. Jiang, F. Zhao, S. Liu, Y. Zhang, Z. Xu and J. Xu, Chem. Commun., 2013, 49, 273-275.

18 C. Ma, B. Xu, G. Xie, J. He, X. Zhou, B. Peng, L. Jiang, B. Xu, W. Tian, Z. Chi, S. Liu, Y. Zhang and J. Xu, Chem. Commun., 2014, 50, 7374-7377.

19 B.-K. An, S.-K. Kwon, S.-D. Jung and S. Y. Park, J. Am. Chem. Soc., 2002, 124, 14410-14415.

20 B.-K. An, D.-S. Lee, J.-S. Lee, Y.-S. Park, H.-S. Song and S. Y. Park, J. Am. Chem. Soc., 2004, 126, 10232-10233.

21 S. Dong, Z. Li and J. Qin, J. Phys. Chem. B, 2009, 113, 434-441. 22 Y. Dong, J. Zhang, X. Tan, L. Wang, J. Chen, B. Li, L. Ye, B. Xu, B. Zou and W. Tian, J. Mater. Chem. C, 2013, 1, 7554-7559.

23 G.-G. Shan, H.-B. Li, H.-Z. Sun, D.-X. Zhu, H.-T. Cao and Z.-M. Su, J. Mater. Chem. C, 2013, 1, 1440-1449.

24 G.-G. Shan, H.-B. Li, H.-T. Cao, D.-X. Zhu, P. Li, Z.-M. Su and Y. Liao, Chem. Commun., 2012, 48, 2000-2002.

25 J. Chen, S. Ma, J. Zhang, L. Wang, L. Ye, B. Li, B. Xu and W. Tian, J. Phys. Chem. Lett., 2014, 5, 2781-2784. 